\title{
Colopleural fistula after hiatal hernia repair
}

\author{
Annemieke M Peters van Ton, ${ }^{1}$ Arjen L Diederik, ${ }^{2}$ David $\mathrm{H}$ Tjan ${ }^{1}$
}

${ }^{1}$ Department of Intensive Care Medicine, Gelderse Vallei Hospital, Ede, The Netherlands ${ }^{2}$ Department of Radiology, Gelderse Vallei Hospital, Ede, The Netherlands

\section{Correspondence to} David H Tjan, tjand@zgv.nl

Accepted 2 August 2016

\section{DESCRIPTION}

A 66-year-old man presented to our emergency department with pneumosepsis in December 2015. His history includes gastric adenocarcinoma for which he underwent an oesophagogastrectomy in 2014. A rare complication $\left(<1 \%{ }^{1}\right)$ occurred. $\mathrm{He}$ developed a symptomatic diaphragmatic hernia which was surgically corrected with a dual mesh mat in June 2015. Three months later he was admitted with a fluid collection in his abdomen and an intrapulmonary abscess. He improved on antibiotic treatment. Two weeks after cessation of antibiotics the patient presented with severe pneumosepsis. A CT scan showed a collection in the pleural cavity with an adjoining abdominal abscess in the left upper quadrant. Fistulas to the colon and the lung were suspected due to the close anatomical relationship and the presence of air-fluid levels in the pleural cavity. A percutaneous drain was placed under CT-guidance in the abdominal abscess. $300 \mathrm{~mL}$ of Xenetix contrast diluted in saline was injected through the drain and the fistulogram revealed a colopleural fistula (figures 1 and 2). Advantages of CT fistulography over conventional fistulography include a high-contrast resolution and multiplanar reconstruction.
The patient was treated with antibiotics and percutaneous drainage. Cultivates did not reveal microorganisms. After 3 weeks of antibiotics patient underwent exploratory laparotomy to remove the diaphragmatic mat; however, although his abdomen was very adhesive, no signs of an active mat infection could be demonstrated. The patient was treated for empyema. He was discharged from the hospital and is still recovering. This clinical image beautifully presents the management of a rare and life-threatening colopleural fistula.

\section{Learning points}

- Colopleural fistulas are rare but life-threatening.

- Conservative therapy including antibiotic treatment and percutaneous drainage can be effective in the treatment of colopleural fistulas.

- CT fistulography is a superior diagnostic tool compared to conventional fistulography.
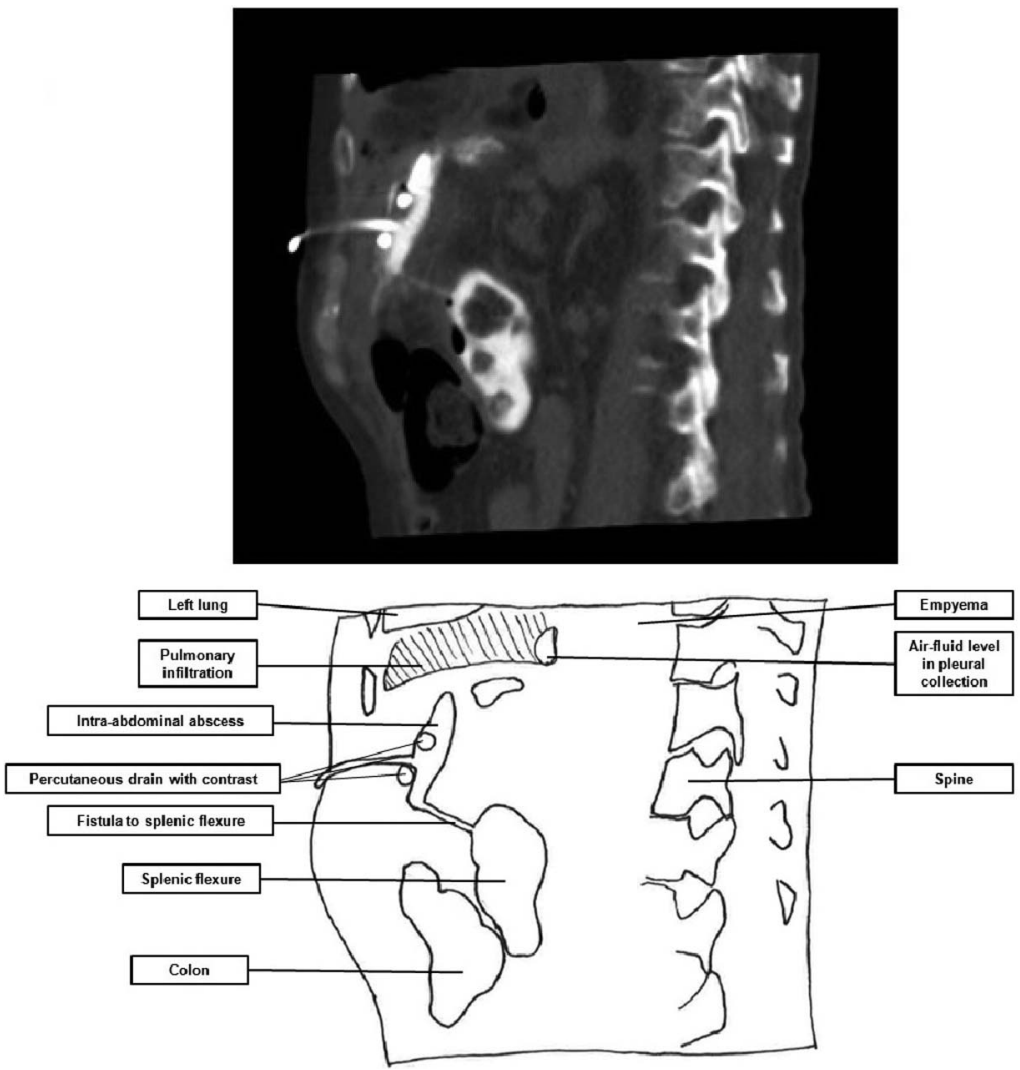

Figure 1 A sagittal reconstruction CT scan presenting a fistula between the abdominal abscess and the colon and empyema surrounding the left lung. 
Figure 2 A coronal reconstruction CT scan presenting a fistula between the abdominal abscess and a collection in the left pleural cavity, an infected foreign body which was the dual mesh mat and a mild pericarditis. Gallstones were an incidental finding.
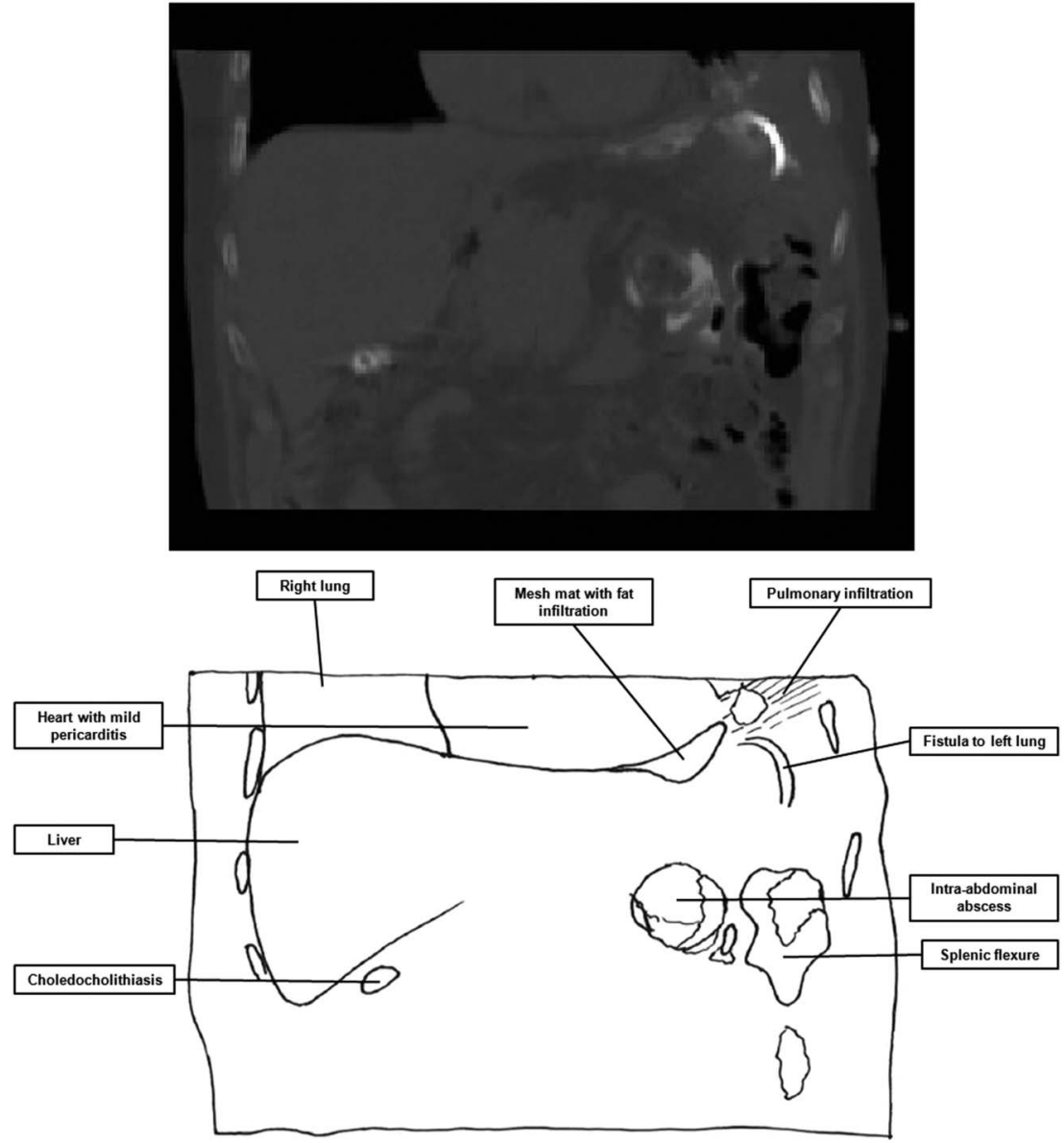

Contributors AMPvT planned the work, drafted the manuscript and formatted the images. ALD obtained the fistulogram and provided the images. All authors have contributed equally in revising the manuscript. DHT supervised the work and he was responsible for the overall content as guarantor.

Competing interests None declared.

Patient consent Obtained.
Provenance and peer review Not commissioned; externally peer reviewed.

\section{REFERENCE}

1 Price TN, Allen MS, Nichols FC, et al. Hiatal hernia after esophagectomy: analysis of , 182 esophagectomies from a single institution. Ann Thorac Surg 2011;92:2041-5.

Copyright 2016 BMJ Publishing Group. All rights reserved. For permission to reuse any of this content visit http://group.bmj.com/group/rights-licensing/permissions.

BMJ Case Report Fellows may re-use this article for personal use and teaching without any further permission.

Become a Fellow of BMJ Case Reports today and you can:

- Submit as many cases as you like

- Enjoy fast sympathetic peer review and rapid publication of accepted articles

- Access all the published articles

- Re-use any of the published material for personal use and teaching without further permission

For information on Institutional Fellowships contact consortiasales@bmjgroup.com

Visit casereports.bmj.com for more articles like this and to become a Fellow 